\title{
Persistent engrailed Expression Is Required to Determine Sensory Axon Trajectory, Branching, and Target Choice
}

\author{
Bruno Marie, ${ }^{1}$ Lillian Cruz-Orengo, ${ }^{2}$ and Jonathan M. Blagburn ${ }^{1,2}$ \\ 1/nstitute of Neurobiology and 2Department of Physiology, Medical Sciences Campus, University of Puerto Rico, \\ San Juan, Puerto Rico 00901
}

\begin{abstract}
The transcription factor Engrailed (En) directs, in the cockroach cercal system, the shape of the axonal arborization and the choice of postsynaptic partners of an identified sensory neuron $(6 \mathrm{~m})$. Knock-out of En using double-stranded RNA interference transforms $6 \mathrm{~m}$ so that it resembles a neighboring neuron that normally does not express the en gene, has a different arbor anatomy, and makes different connections. We characterized the development of $6 \mathrm{~m}$ and perturbed en expression at different stages. Our results show that En is not required before birth for $6 \mathrm{~m}$ to become a neuron, but that it is required in the postmitotic neuron to control axonal arborization and synaptic specificity. Knock-out of En after $6 \mathrm{~m}$ has entered the CNS does not change the axonal trajectory and has minor effects on axonal branches but causes the formation of synaptic connections typical of an
\end{abstract}

Brain function depends on the accurate establishment of synaptic circuits. Initial selection of axonal pathways is directed by cellspecific combinatorial expression of transcription factors (Thor and Thomas, 1997; Landgraf et al., 1999; Thor et al., 1999; Kania et al., 2000). The homeodomain-containing protein Engrailed (En) regulates axonal pathfinding in a population of spinal cord association interneurons (Saueressig et al., 1999). En controls the expression of ephrins in the tectum (Logan et al., 1996; Shigetani et al., 1997) and thus affects the axonal projections of retinal neurons (Friedman and O'Leary, 1996; Itasaki and Nakamura, 1996). In Drosophila, postmitotic neuronal en expression represses the cell adhesion molecules connectin and neuroglian, thus affecting axon morphology in the central and peripheral nervous systems (Siegler and Jia, 1999). There is emerging evidence that cell-specific transcription factors also control later stages of circuit formation, such as the formation of a termination zone (Arber et al., 2000) and the selection of synaptic inputs (Miller and Niemeyer, 1995; Winnier et al., 1999). En itself may also control synaptic target recognition. The expression of en-1 in spinal cord interneurons appears to correlate with the formation of synapses with motoneurons (Wenner et al., 2000).

The recent cloning of the two en genes from the cockroach Periplaneta americana (Marie and Bacon, 2000) allowed us to use

Received Aug. 16, 2001; revised Oct. 25, 2001; accepted Nov. 6, 2001.

This work was supported by National Institutes of Health (NIH) Grant NS07464 to J.M.B. with partial support from NIH Research Centers in Minority Institutions Award G12 RR-03051. We thank Dr. Deborah Baro for the use of her molecular biology facilities and Dr. Jonathan Bacon for constructive criticism of this manuscript.

Correspondence should be addressed to Dr. Jonathan M. Blagburn, Institute of Neurobiology, 201 Boulevard del Valle, San Juan, Puerto Rico 00901. E-mail: jmblagbu@neurobio.upr.clu.edu.

Copyright (ㄷ) 2002 Society for Neuroscience $\quad 0270-6474 / 02 / 220832-10 \$ 15.00 / 0$
En-negative cell. This suggests that En controls target recognition molecules independently from those guiding the axon. In contrast, double-stranded RNA injection $1 \mathrm{~d}$ later does not have any effects on the phenotype of $6 \mathrm{~m}$, suggesting that the period of synapse formation is over by the time En levels have fallen or, if synapse turnover occurs, that En is not required to maintain the specificity of synaptic connections. We conclude that persistent en expression is required to determine successive stages in the differentiation of the neuron, suggesting that it is not far upstream from those genes encoding axon guidance and synaptic recognition molecules.

Key words: Engrailed; RNA interference; mechanosensory; homeodomain; synaptic specificity; axon guidance double-stranded RNA (dsRNA) interference (Fire et al., 1998) to knock out the En protein. The second larval stage (or instar) of the cockroach has an array of 39 filiform hairs on each cercus, each with an associated sensory neuron. These neurons project to the terminal ganglion and form synapses with defined subsets of "giant" interneurons (Thompson et al., 1992), thus mediating the animal's escape response to wind. En is normally expressed only by neurons born in the medial part of the cercal epidermis (Blagburn et al., 1995). We showed directly that En controls both the axonal arborization and the synaptic connectivity of an identified medial sensory neuron (Marie et al., 2000a; summarized in Fig. 1).

An insect mechanosensory neuron is generated by a fixed lineage from an ectodermal precursor (Ghysen and DamblyChaudiere, 2000). The neuron then sends an axon to the CNS, where it synapses with appropriate targets. At which time(s) in this sequence of development is expression of en required to determine axonal arbor type and synaptic connectivity? We now have the opportunity to dissect the temporal role of this transcription factor. The objectives of this study are to describe the developmental timetable of the $6 \mathrm{~m}$ neuron, to measure the lifetime of the En protein after dsRNA injection, and then to determine the effects of En knock-out at different times during the development of the neuron. We find that persistent expression of en is required in the postmitotic neuron to control each successive stage of its development: choice of axonal pathway, establishment of a branching pattern, and, finally, recognition of synaptic targets.

Parts of this paper have been published previously in abstract form (Marie et al., 2000b).

\section{MATERIALS AND METHODS}

$d s R N A$ interference. A mixture of dsRNAs corresponding to a $609 \mathrm{bp}$ Pa-en1 PCR fragment [bases 278-886, European Molecular Biology 


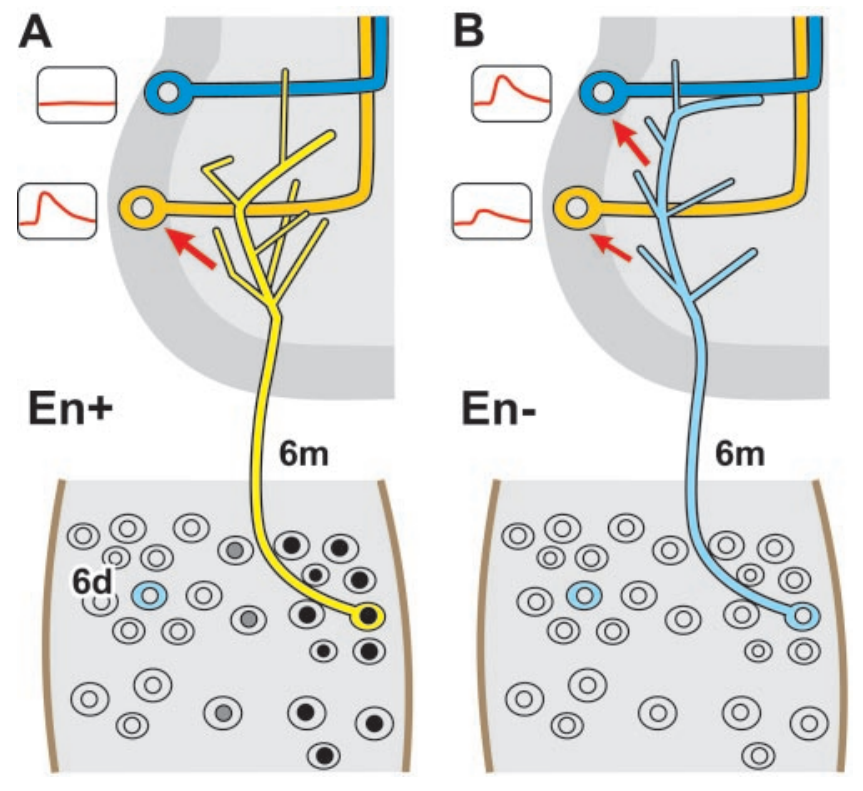

Figure 1. Diagram representing the results of a previous study (Marie et al., 2000a) illustrating a portion of the cercal epidermis and its array of second instar neurons. A, Medial sensory neurons express En (dark nuclei). The identified neuron studied, $6 \mathrm{~m}$, has a characteristic axonal arbor in the terminal abdominal ganglion. $6 \mathrm{~m}$ normally forms synaptic connections (red arrow) with certain target interneurons (orange) and not with others (blue). B, After En knock-out with dsRNA injection shortly after hatching, the arbor type of $6 \mathrm{~m}$ is altered so that it resembles that of a neighboring, laterally positioned neuron $6 \mathrm{~d}$ (blue), which does not normally express En. The pattern of synaptic connections made by $6 \mathrm{~m}$ is also altered, reducing the strength of its normal connections and forming new synapses with inappropriate targets (blue).

Laboratory (EMBL) accession number AJ243883] and a 546 bp Pa-en2 PCR fragment (bases 718-1263, EMBL accession number AJ243884) was synthesized as described previously (Marie et al., 2000a). The dsRNAs were resuspended in injection buffer (in mM: 20 Tris, $\mathrm{pH} 7.8$, and $150 \mathrm{NaCl})$ and mixed at a concentration of $1.5 \mu \mathrm{M}$ of each dsRNA. First instar animals at different stages of development were immobilized on ice and injected twice (injection volume was $150 \mathrm{nl}$ ) through the broken tips of the cerci. Embryos at the 90-93\% stage of development were removed from the oothecae and egg case, injected once through the abdominal wall, and left incubating in a humid chamber at $30^{\circ} \mathrm{C}$ until hatching. The specificity of double-stranded RNA interference (dsRNAi) in this system was demonstrated previously (Marie et al., 2000a) by application of Pa-en1 and Pa-en2 dsRNAs separately and by application of injection buffer only.

En immunocytochemistry. First instar animals were placed in saline, and the dorsal tergites and gut were removed. The distal two segments of the cerci were cut off, and fixative was added to the dissection chamber. The dorsal side of each cercus was then cut off, exposing the interior. Tracheae, the cercal nerves, connective tissue, and as many fat body cells as possible were removed with fine forceps to improve access and visibility of the sensory neurons. Fat body cells in particular tend to show strong granular avidin binding in the cytoplasm. Animals were fixed for $1 \mathrm{hr}$ in $4 \%$ paraformaldehyde and $0.075 \mathrm{M}$ PBS before washing thoroughly in PBS. After a preincubation in normal horse serum and PBS plus $0.3 \%$ Triton X-100 (PBST) for $30 \mathrm{~min}$, monoclonal 4D9 anti-En antibody, obtained from the Developmental Studies Hybridoma Bank (University of Iowa, Iowa City, IA) or as a gift from Dr. Corey Goodman, was applied at a dilution of 1:20 in PBST for $15-20 \mathrm{hr}$ at $4^{\circ} \mathrm{C}$. After three $10 \mathrm{~min}$ washes, biotinylated horse anti-mouse antibody (Vector Laboratories, Burlingame, CA) was applied at a dilution of 1:200 for $1 \mathrm{hr}$ at room temperature and the tissue was again washed three times. After incubation in avidin-peroxidase complex (Vector Laboratories) for $1 \mathrm{hr}$ at room temperature, the tissue was washed; a solution of $0.1 \% \mathrm{DAB}$ with $0.03 \% \mathrm{H}_{2} \mathrm{O}_{2}$ was added to the wells; and the reaction was allowed to proceed for $20 \mathrm{~min}$. The specimens were washed in PBS and then cleared and mounted in $70 \%$ glycerol. Images were captured with a Zeiss
(Thornwood, NY) Axiocam CCD camera. Percent gray scale levels of the sample areas (nucleus of $6 \mathrm{~m}$ or the medial epidermis of segments 5-7) and the corresponding background areas (nucleus of $6 \mathrm{~d}$ or the lateral epidermis of segments 5-7) were measured using Adobe (Mountain View, CA) Photoshop. Background percent gray levels were subtracted from the sample values.

5-Bromo-2'deoxyuridine-5'triphosphate application in vivo and immunocytochemistry. Staged newly hatched animals were immobilized on ice, and a solution of $10^{-2} \mathrm{~m} 5$-bromo-2' deoxyuridine-5'triphosphate (BrdU; Sigma, St. Louis, MO), $150 \mathrm{~mm} \mathrm{NaCl}$, and $10 \mathrm{~mm}$ 4-morpholinepropanesulfonic acid was injected into their hemolymph through the broken end of the cercus. The animals were then left to develop for $5 \mathrm{~d}$ (a stage at which all the sensory neurons are identifiable), dissected as described above, fixed for $1 \mathrm{hr}$ in $4 \%$ paraformaldehyde and $0.075 \mathrm{M} \mathrm{PBS}$, and washed in PBST for $45 \mathrm{~min}$. To denature the DNA, the preparations were incubated in a $2 \mathrm{~N} \mathrm{HCl}$ solution for $1 \mathrm{hr}$ before being washed in PBST for $1 \mathrm{hr}$. After a preincubation in normal horse serum and PBST for $45 \mathrm{~min}$, monoclonal anti-BrdU antibody (Sigma) was applied at a dilution of 1:1000 in PBST for $15 \mathrm{hr}$ at $4^{\circ} \mathrm{C}$. The subsequent applications of biotinylated antibody and avidin-peroxidase complex and the staining development were performed as described above.

1,1'-Dioctadecyl-3,3,3'-tetramethylindocarbocyanine perchlorate staining. The CNS and cerci were dissected and fixed in $4 \%$ formaldehyde for $1 \mathrm{hr}$. 1,1'-Dioctadecyl-3,3,3'-tetramethylindocarbocyanine perchlorate (DiI; Molecular Probes, Eugene, OR) dissolved in dimethylformamide at an approximate concentration of $3 \%$ was injected into both sides of the neuropil of the fixed terminal ganglion, using a broken micropipette. The preparations were left in fixative overnight at $30^{\circ} \mathrm{C}$ and then examined with a epifluorescence microscope.

Intracellular recording and filiform hair stimulation. Electrodes for intracellular recording from giant interneuron (GI) cell bodies were filled with $1 \mathrm{M} \mathrm{KCl}$ and had a resistance of 60-120 M $\Omega$. Cell bodies of GIs were identified by using the standard criteria of size, appearance, and position in relation to ganglionic landmarks (Blagburn, 1989; Blagburn and Thompson, 1990). The GI was designated as ipsilateral or contralateral according to the position of its cell body, not of its axon. Recordings were rejected if the resting membrane potential stabilized at values more positive than $-60 \mathrm{mV}$; most GIs had membrane potentials of -65 to -80 $\mathrm{mV}$. The frequency of action potentials in the sensory neuron was increased by pushing the hair in its preferential direction briefly, using a micropipette with a petroleum jelly-covered tip mounted on a loudspeaker connected to a pulse generator. This increase in sensory neuron firing rate reliably results in a burst of monosynaptic EPSPs with a short (4-6 msec), constant latency (Thompson et al., 1992) in the reference GI. Data were recorded on videotape for later playback into a computer data acquisition system (Axoscope; Axon Instruments) with which the amplitude of the first unitary EPSP in the burst was measured.

Lucifer yellow injections. After electrophysiological experiments, individual sensory neurons were identified with Nomarski optics and impaled with glass microelectrodes back-filled with $4 \%$ Lucifer yellow. Hyperpolarizing current $(-2 \mathrm{nA})$ was applied through the microelectrode for $8-10 \mathrm{~min}$, and then the preparation was fixed in $4 \%$ paraformaldehyde and $0.075 \mathrm{M}$ PBS for $1 \mathrm{hr}$. After thorough washing in PBS, preparations were preincubated in normal goat serum and then incubated in 1:2000 anti-Lucifer yellow antibody (Molecular Probes) for $15-20 \mathrm{hr}$ at $4^{\circ} \mathrm{C}$. After washing and incubation in biotinylated goat anti-rat antibody (Vector Laboratories), the ABC reaction was performed as described above. A through-focus series of images was made of each arborization with the CCD camera, and then in-focus regions were combined using the layer mask option of Adobe Photoshop.

\section{RESULTS}

\section{$6 \mathrm{~m}$ is born between 4 and $9 \mathrm{hr}$ after hatching}

At what time is $6 \mathrm{~m}$ born? We injected BrdU into the animals at different times after hatching and asked whether BrdU staining is detectable at day 5 when the entire set of second instar sensory neurons is identifiable. When BrdU is injected $4 \mathrm{hr}$ after hatching, the nucleus of $6 \mathrm{~m}$ is labeled (Fig. $2 A$ ) because the immediate precursor of neuron $6 \mathrm{~m}$ incorporates BrdU during $\mathrm{S}$ phase before the division at which $6 \mathrm{~m}$ is born. When injected at $9 \mathrm{hr}, 6 \mathrm{~m}$ is not labeled (Fig. 2B), demonstrating that, at this time, $6 \mathrm{~m}$ is already a postmitotic neuron. This indicates that $6 \mathrm{~m}$ is born between 4 and $9 \mathrm{hr}$ after hatching. 

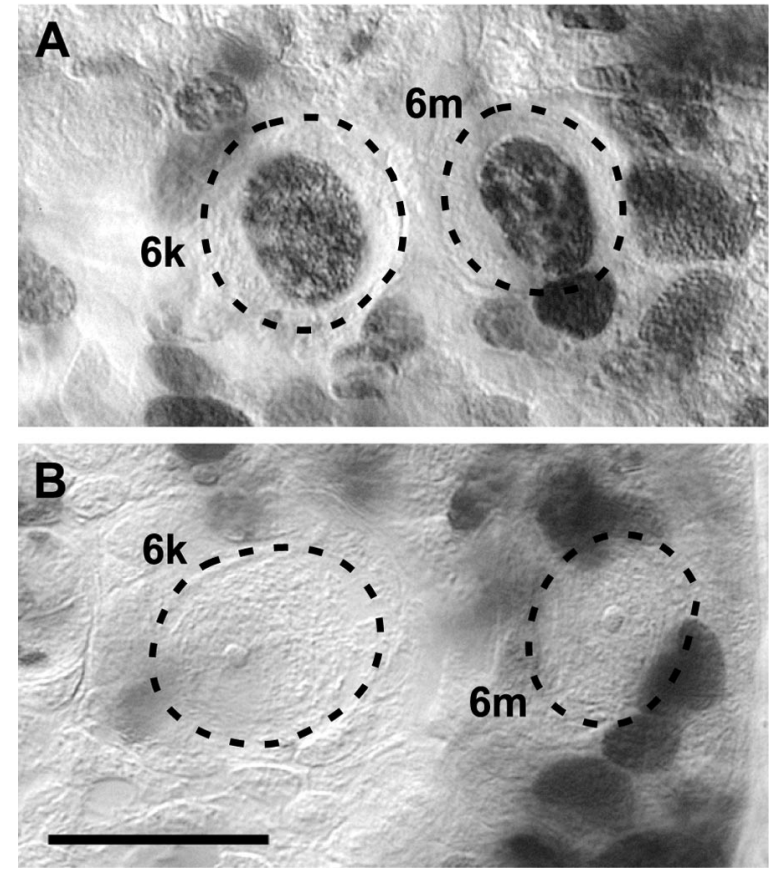

Figure 2. The neuron $6 \mathrm{~m}$ is born between 4 and $9 \mathrm{hr}$ after hatching. $A$, After injection of BrdU into the animal at $4 \mathrm{hr}$ after hatching, the cerci were processed with anti-BrdU antibody at $6 \mathrm{~d}$, when all the neurons were differentiated. $6 \mathrm{~m}$ and its neighbor $6 \mathrm{k}$ have stained nuclei. $B$, BrdU staining after injection at $9 \mathrm{hr}$ after hatching shows no immunoreactivity in the nuclei of $6 \mathrm{~m}$ and $6 \mathrm{k}$. Scale bar, $20 \mu \mathrm{m}$.

\section{The axon of $6 \mathrm{~m}$ enters the CNS on day 3}

When do the cercal sensory axons enter the terminal ganglion and form their arborizations? Retrograde staining of the axons using DiI shows that both $6 \mathrm{~m}$ and $6 \mathrm{~d}$ have axons in the terminal ganglion by day 3 of the first instar. Crystals of DiI were deposited in the fixed ganglion at different times after hatching, and the proximal segments of cerci were examined with epifluorescence $1 \mathrm{~d}$ later (Fig. 3A). Several such preparations were examined for each day of the first instar to build up a timetable of sensory axon growth (Fig. 3B). By convention, the eight incipient second instar segments are numbered distal to proximal; Figure 3 shows only segments $3-7$. If a neuron was retrogradely stained in $>50 \%$ of the preparations for that day, it was scored as having entered the CNS. At hatching (day 0) the original two sensory neurons, 3L and $3 \mathrm{M}$, and some of the neurons in segment 4 already have axons in the CNS (Fig. 3A,B). By day 3, several more neurons have axons in the CNS, including $6 \mathrm{~m}$ and $6 \mathrm{~d}$ (Fig. $3 A, B$ ). By day 7 , all the sensory neurons have axons in the terminal ganglion neuropil before molting to the second instar on day 8 or 9 . Neurons born more distally on the cercus tend to enter the CNS earlier (Fig. $3 B$ ); however, the axonal ingrowth does not proceed segment by segment. For example, the distal $4 \mathrm{f}$ neuron grows in relatively late on day 4, unlike its neighbors, which have axons in the CNS at hatching.

\section{Development of $6 \mathrm{~m}$ arborization}

The developing sensory neurons can be seen in the cercal epidermis using Nomarski optics. Neuron $6 \mathrm{~m}$ was impaled with intracellular microelectrodes and injected with Lucifer yellow on different days after hatching. As suggested by DiI staining, the axon enters the neuropil of the terminal ganglion on day 3 (Fig. $4 A$ ), its growth cone following the main filiform hair sensory axon tract. A few hours later (Fig. $4 B$ ), the axon of $6 \mathrm{~m}$ has passed the choice point at which the lateral (L) and medial (M) axon tracts diverge, establishing its medial bend, characteristic of an M-type trajectory. By days 4 and 5, secondary branches are forming, in particular the dorsally projecting branches that are characteristic of an M-type arbor (Fig. 4C,D). Although many temporary filopodia are formed, the branches themselves appear to be stereotyped in pattern, with little evidence of overgrowth and subsequent pruning. This is similar to the pattern of growth of embryonic axons in the cockroach (Blagburn et al., 1996) and the cricket (Shankland, 1981). By day 5, tertiary branches form, and by day 6 , the arborization is almost complete, with only the terminals of the dorsal-most branches still showing evidence of growth (Fig. 4D,E).

\section{Establishment of $6 \mathrm{~m}$ synaptic connections on day 6}

When do the synaptic connections between second instar filiform hair sensory neurons and giant interneurons develop? Developing sensory neurons may be spontaneously active (Blagburn et al., 1996); therefore, if they did form synapses early, it would increase the synaptic noise in the GIs without conveying any useful information about air movements, because the new filiform hairs themselves remain under the cuticle until molting. Classic experiments on the crayfish tail fan sensory system suggest that new afferents must wait until a period of molting before synapse formation can take place (Krasne and Lee, 1982). To answer this question for $6 \mathrm{~m}$, we took advantage of the fact that the soma can be identified within the epidermis of the first instar cercus, several days before the molt to second instar on days 8 and 9. Dual intracellular recordings were made from the cell bodies of target GIs and $6 \mathrm{~m}$ (Fig. 5A). Depolarizing current pulses injected into $6 \mathrm{~m}$ elicited action potentials (Fig. $5 B$ ). On day 5 , no postsynaptic responses could be observed (data not shown), but by day 6 , after apolysis of the first instar cuticle has taken place, a large unitary EPSP could be evoked in GI 2 by each action potential in $6 \mathrm{~m}$ (Fig. $5 B)$. Thus, although synapse formation does precede molting proper, it appears to be correlated with cuticular apolysis and the concomitant rise in circulating ecdysteroids (for review, see Riddiford, 1993).

\section{The half-life of the En protein is $\sim \mathbf{3 0} \mathrm{hr}$}

It is now well established that dsRNAi acts quickly in catalyzing the degradation of the targeted endogenous RNA (Montgomery et al., 1998). Nevertheless, as a prelude to the subsequent functional tests, it was necessary to monitor the actual time course of reduction in levels of En protein after RNAi. Shortly after hatching, animals were injected twice with $450 \mathrm{fmol}$ of a mixture of dsRNA from the two cockroach engrailed genes, Pa-en1 and Pa-en2 (Marie and Bacon, 2000). We then fixed animals at different times after the injection and used the 4D9 antibody (Patel et al., 1989) to detect levels of the En protein in flattened cerci, following previous methods (Blagburn et al., 1995). Four regions were defined for the purpose of quantification: the nuclei of neurons $6 \mathrm{~m}$ and $6 \mathrm{~d}$ and the medial and lateral regions of incipient second instar segments 5-7 (Fig. 6A). The mean pixel gray levels were determined, and the values for unstained tissue (6d and lateral epidermis) were subtracted from the values for the stained regions ( $6 \mathrm{~m}$ and medial epidermis). Values from different experiments were standardized as a percentage of the maximum staining intensity (Fig. 6D).

Although En staining in a control animal is constant from day 0 to day 6 of postembryonic development (data not shown), after 
A

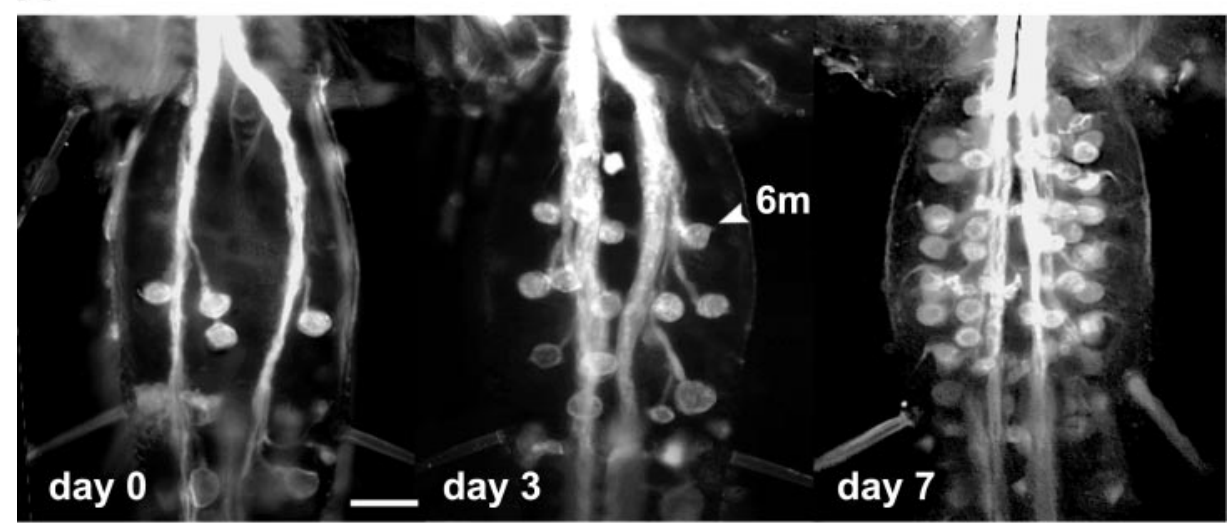

B day 0

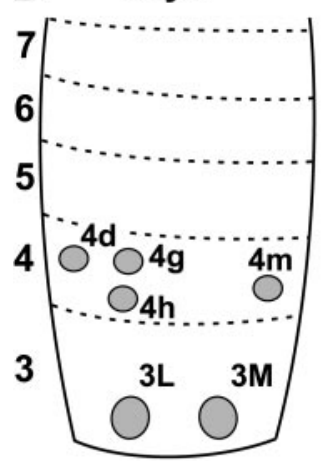

day 4
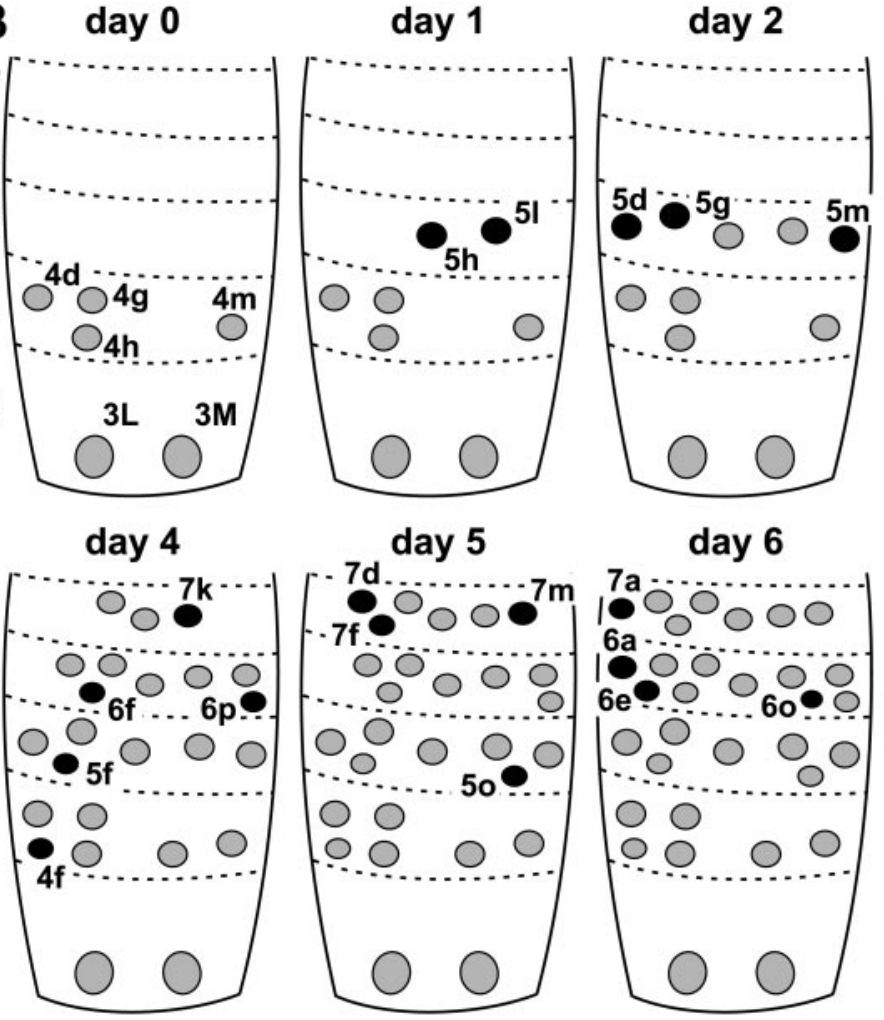

day 6

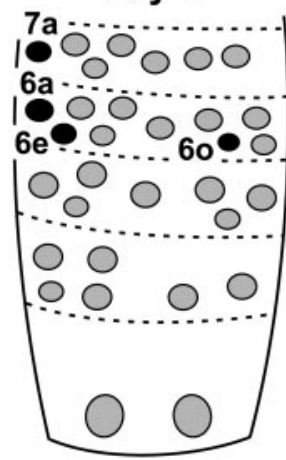

dsRNAi, En staining declines over a prolonged period, with faint staining remaining after $65 \mathrm{hr}$ (Fig. 6D). By $125 \mathrm{hr}$ (day 5), En staining is almost undetectable, particularly in the nuclei of medial neurons (Fig. $6 C, D$ ). The time taken for En staining to decline to $50 \%$ of its initial level is $\sim 30 \mathrm{hr}$ after dsRNA injection.

How quantitative is the ABC-peroxidase reaction? Because of steric hindrance, this reaction is very sensitive to small amounts and tends to saturate with strong staining; therefore, it is not linear, and low levels may be exaggerated (but see Nibbering et al., 1986). The decrease in En may therefore be more rapid and the half-life may be shorter than we have estimated. However, this does not affect the interpretation of our experimental results. How long does dsRNAi last? We performed En immunostaining of cerci from animals injected on day -3 and fixed on day 6 and did not detect any staining (data not shown); therefore, the knock-out effect lasts for at least $9 \mathrm{~d}$.

As summarized in Figure 7, we have characterized the development of neuron $6 \mathrm{~m}$ from its birth to the establishment of its

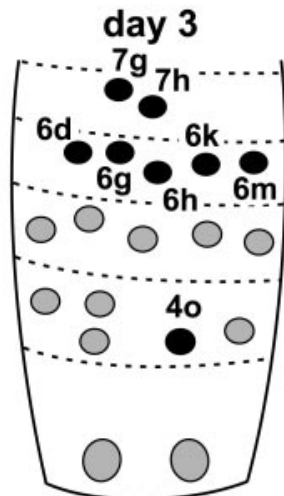

day 7

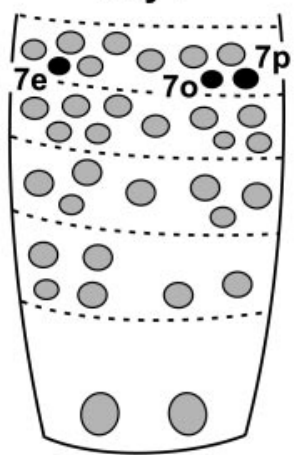

Figure 3. Cercal sensory axons enter the terminal ganglion at different times. $A$, Flattened whole mounts of the proximal segments of first instar left cerci. DiI dissolved in dimethylformamide was injected into the fixed terminal abdominal ganglion at different days after hatching (day 0$)$. This stained the axons and cell bodies of sensory neurons that had reached the neuropil. $B$, DiI staining enabled the average time at which the axon of each neuron entered the CNS to be determined. The diagram shows segments 3-7, with the incipient segmental boundaries indicated by dashed lines. Newly stained neurons are shown as filled ellipses; those that have entered the CNS earlier are gray. The first instar neurons, $3 L$ and $3 M$, enter the neuropil in the embryo, as do some of the segment 4 neurons.

first synaptic connections. In conjunction with this developmental timetable, we have also established the time required for the disappearance of En protein after RNAi. These data allow us, by injecting en dsRNA at different times, to affect $6 \mathrm{~m}$ neuron at different times during its development (Fig. 7): before its birth (dsRNA injection at day -3); after its birth but before its axon has entered the CNS (dsRNA injection at day 0); after the establishment of the major branches but before the establishment of synaptic connections (dsRNA injection at day 3); and at a later stage when En protein is not fully reduced until after the establishment of synaptic connections (dsRNA injection at day 4).

\section{Knock-out of En at different times affects different phases of axon guidance}

In control animals, the arborization of $6 \mathrm{~m}$ within the terminal ganglion neuropil has several characteristic, stereotyped features, which can be quantified after Lucifer yellow injection and antibody intensification (Fig. $8 A$ ). The first of these to be established 

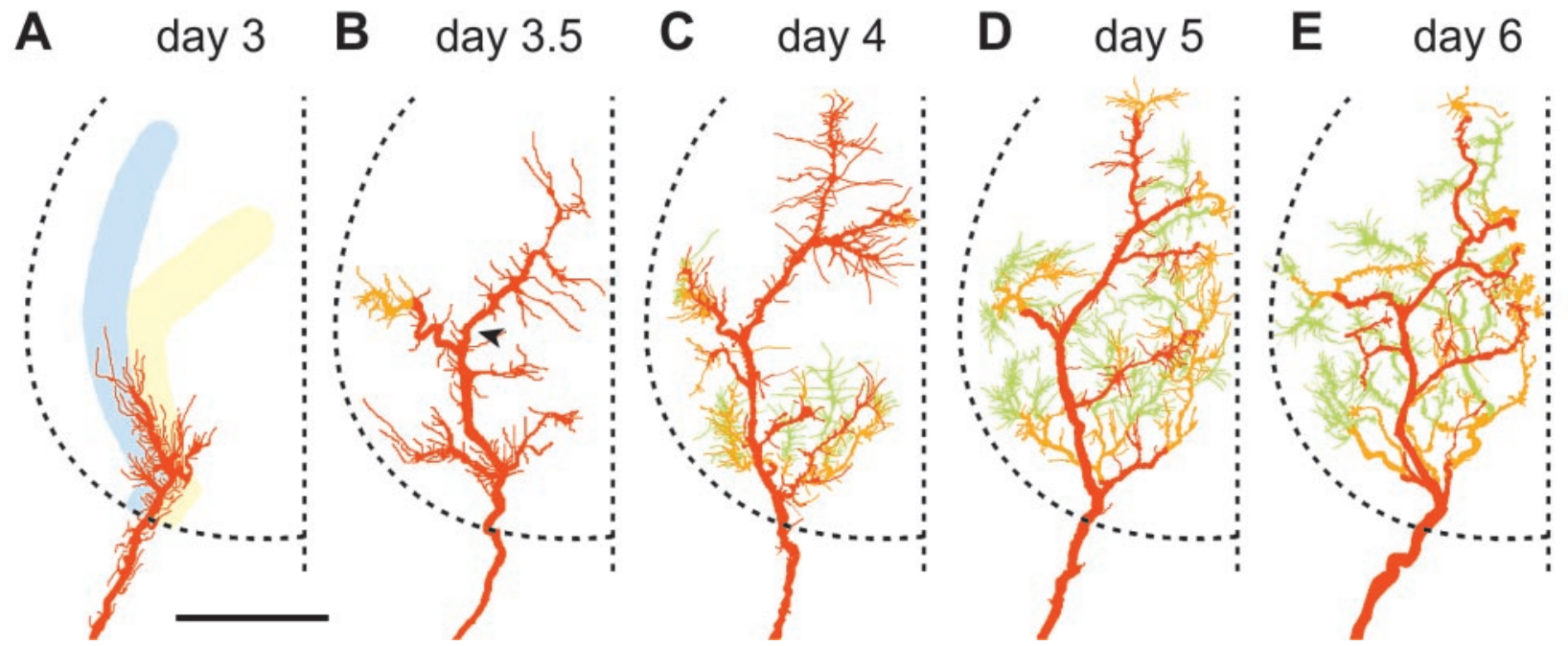

Figure 4. Lucifer yellow filling of the axon of $6 \mathrm{~m}$ as it enters the neuropil of the terminal abdominal ganglion and forms its arborization. Branches in the ventral third of the cercal glomerulus are shown in red; those in the central third are shown in orange; and those that enter the dorsal third of the neuropil are shown in green. A, On day 3 after hatching, the axon of $6 \mathrm{~m}$ enters the neuropil, elongating along the preexisting $\mathrm{L}$ and $\mathrm{M}$ tracts ( pale blue, pale yellow). $B$, Midway through day $3,6 \mathrm{~m}$ has formed the characteristic axon bend (arrowhead) and is starting to extend side branches. $C, D$, Through days 4 and 5, the axon elaborates its secondary and tertiary branches. $E$, By day 6 , the arbor is essentially complete, although filopodia remain on the branch tips. Scale bar, $50 \mu \mathrm{m}$.

A

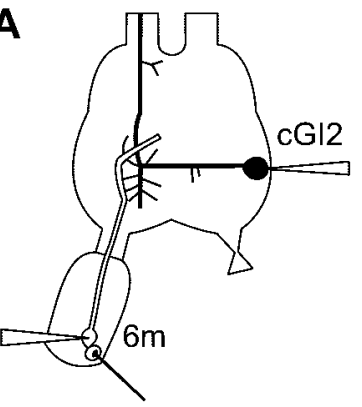

B

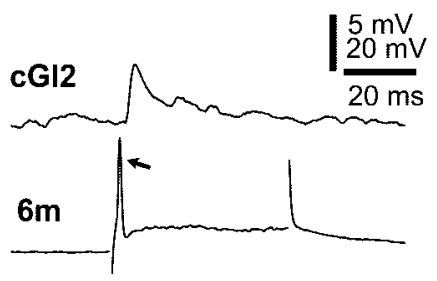

Figure 5. Neuron $6 \mathrm{~m}$ has formed synaptic connections by day $6 . A$, Diagram of the recording setup. A double intracellular recording is made from the soma of $6 \mathrm{~m}$ within the cercal epidermis and that of cGI2 in the terminal abdominal ganglion. $B$, A depolarizing current pulse (data not shown) stimulates an action potential in $6 \mathrm{~m}$ (arrow), which elicits a monosynaptic EPSP in contralateral GI2.

as the axon grows through the neuropil is the medial bend (see above). This reflects an axonal guidance decision made in which the $\mathrm{L}$ and $\mathrm{M}$ afferent tracts diverge (Fig. 4A). The angle of this bend from the anteroposterior axis is $35-40^{\circ}$ in M-type axons such as $6 \mathrm{~m}$. L-type axons such as $6 \mathrm{~d}$ do not make this abrupt change in pathway; the angle subtended by the equivalent region of their axons is $10-20^{\circ}$ (Fig. $8 F, I$ ). Another characteristic is that M-type axons do not innervate the anterolateral region of the cercal glomerulus (Fig. 8A,G,J), whereas L-type axons do. The final stage of the formation of the $6 \mathrm{~m}$ arbor involves the elaboration of branches in the dorsal region of neuropil (Fig. 8H,K). These dorsal branches are also diagnostic of M-type axons and are not formed by L-type axons such as $6 \mathrm{~d}$.

What are the effects of En knock-out before the final mitosis that generates the $6 \mathrm{~m}$ sensory neuron? Because $6 \mathrm{~m}$ is born shortly after hatching, and because removal of En protein takes $\sim 3 \mathrm{~d}$, it was necessary to inject dsRNA into $27 \mathrm{~d}$ embryos and culture them ex ovo for the remaining $3 \mathrm{~d}$ before hatching. This did not produce any obvious disruption of the formation or patterning of filiform hair sensilla, although a distortion in the medial edge of

the cercal cuticle was consistently seen, along with a small change in the relative positions of some of the more medial sensilla (data not shown). These changes are probably attributable to alterations in the pattern of cuticular and epidermal stretching immediately after the molt to second instar. Sensory neuron $6 \mathrm{~m}$ could reliably be identified in these animals, and Lucifer yellow fills showed consistent and dramatic changes in the morphology of the arborization, so that it came to resemble that of an L-type neuron (Fig. $8 B$ ). The axon followed the $\mathrm{L}$ afferent tract, thus significantly reducing axon angle (Fig. 8I), and the area of arborization occupying the anterolateral corner of the cercal glomerulus was significantly increased (Fig. $8 J$ ). In addition, the area of branches in the dorsal third of the neuropil was significantly reduced (Fig. $8 K$ ).

Injection of dsRNA shortly after hatching (day 0; Fig. 7) also causes very similar changes in the arborization of $6 \mathrm{~m}$ (Fig. 8C), as shown in the previous study (Fig. 1; Marie et al., 2000a). Axon angle and dorsal area are significantly reduced, whereas the area in the anterolateral region of neuropil is significantly increased (Fig. 8I-K). Knowing the time of birth of $6 \mathrm{~m}$ and the half-life of the En protein, we conclude that the arborization of $6 \mathrm{~m}$ is transformed just as radically by En knock-out in the postmitotic neuron as in the precursor.

Injection of dsRNA at day 3, which should result in a significant reduction in the level of En protein after day 4 (Fig. 7), does not transform the arbor of $6 \mathrm{~m}$ into an L-type arbor (Fig. $8 D$ ). The angle of the medial bend is not reduced, suggesting that the axon cannot alter the choice of the M pathway made on day 3 (Fig. 8I). However, the area of $6 \mathrm{~m}$ branches in the anterolateral quadrant, although significantly less than in embryonically injected animals, is also significantly greater than that of controls (Fig. 8J). Similarly, there is a small but significant reduction in the area of branches in the dorsal third of the neuropil compared with control arbors (Fig. $8 \mathrm{~K}$ ). These results suggest that, despite the constraints imposed by the early choice of the axon pathway, the distribution of more distal secondary and tertiary branches, which are formed on days 5 and 6, can still be altered by En knock-out. 


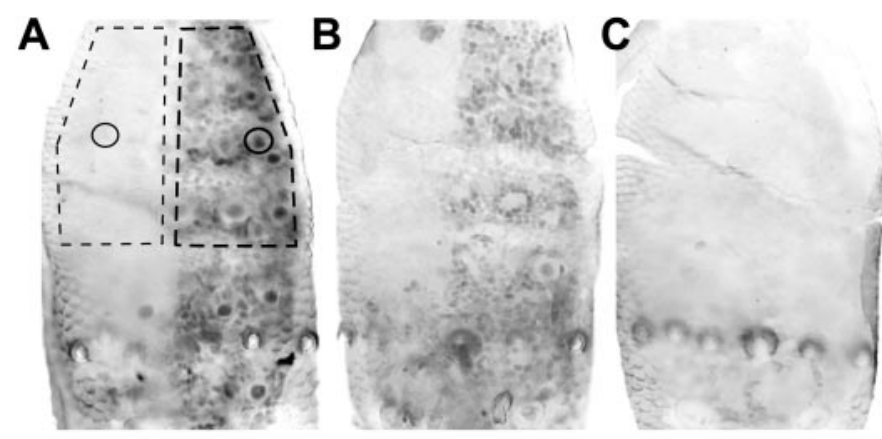

D

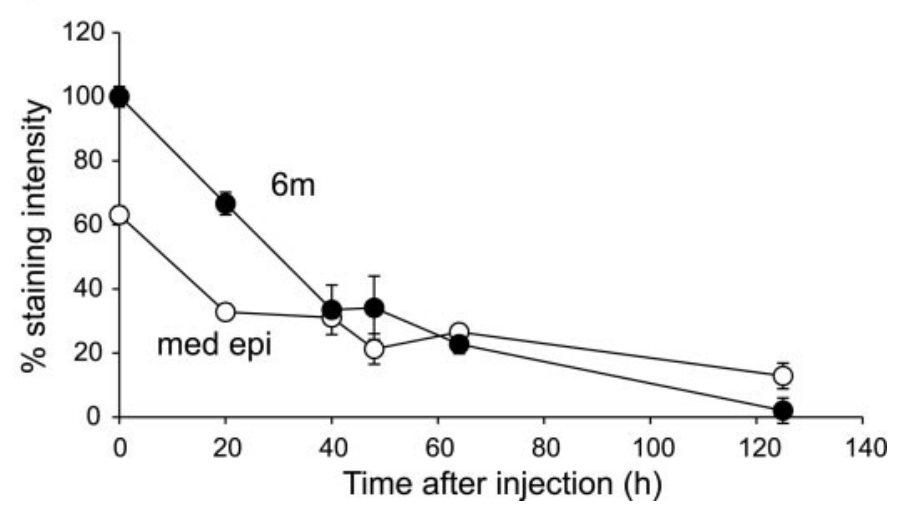

Figure 6. The levels of En protein are reduced gradually after dsRNA injection. $A-C$, Dorsal views of the flattened proximal segment of 6-d-old first instar left cerci, medial to the right, proximal to the top. $A$, En immunostaining with the 4D9 antibody, showing its localization in the nuclei of medial epidermal cells and neurons. Four areas were used for quantification of En staining; the nucleus of $6 \mathrm{~m}$ (bold ellipse), the nucleus of $6 \mathrm{~d}$ (ellipse), the medial epidermis of segments 5-7 (bold dashed outline), and the lateral epidermis of segments 5-7 (dashed outline). B, Cercus 40 $\mathrm{hr}$ after dsRNA injection, showing partial reduction of staining in the epidermis and less staining in the neuronal nuclei. $C$, Cercus $125 \mathrm{hr}$ after dsRNA injection, showing the complete abolition of En staining. $D$, Quantification of En staining intensity at different times after dsRNA injection, measured in the medial epidermis (med epi; open circles) and in the nucleus of $6 \mathrm{~m}$ ( filled circles). The half-life of the En protein is $\sim 30 \mathrm{hr}$. Error bars represent SEM.

Later injection of dsRNA, on day 4, has no significant effects on the arborization of $6 \mathrm{~m}$ (Fig. $8 E, I-K)$.

\section{Temporal effects of En knock-out on synaptic connections}

Patterns of synaptic connections from $6 \mathrm{~m}$ to different GIs were assayed using the methods of previous studies (Thompson et al., 1992; Marie et al., 2000a). Pairs of GIs were recorded intracellularly while the hair of $6 \mathrm{~m}$ was pushed in its excitatory direction (Fig. 9A). If a synaptic connection was present, this resulted in summating bursts of monosynaptic unitary EPSPs (Fig. 9B). The amplitude of the first of these unitary EPSPs was measured.

Injection of dsRNA $3 \mathrm{~d}$ before hatching (day -3; Fig. 9C) removes En protein before the birth of $6 \mathrm{~m}$ (Fig. 7). This results in dramatic changes in the synaptic specificity of the neuron. The normally robust synaptic connections between $6 \mathrm{~m}$ and contralateral GIs 1 and 2 are significantly reduced in amplitude, and the connection with contralateral GI5 (cGI5) disappears entirely. This could simply be the result of a general loss of the ability to form synapses. A more telling measure of the change in synaptic specificity is the appearance of strong de novo connections between $6 \mathrm{~m}$ and ipsilateral and contralateral GI3 and GI6. (Fig.
$9 B, C)$. Thus the pattern of $6 \mathrm{~m}$ synaptic connections becomes similar to that of lateral-type sensory neurons that do not express En (Thompson et al., 1992). For example, neuron 6d normally forms connections $\sim 2 \mathrm{mV}$ in amplitude with GIs 3 and 6 and 1.5 $\mathrm{mV}$ with cGI1 and cGI2 but never contacts ipsilateral GI1 (iGI1), iGI2, iGI5, or cGI5 (Marie et al., 2000a).

Interestingly, in two of four day -3 preparations, $6 \mathrm{~m}$ does not form any direct connection with contralateral GI1 but instead forms a long-latency polysynaptic input (Fig. 9B). This is characteristic of more distal lateral-type neurons such as the first instar 3L neuron (Hill and Blagburn, 1998) rather than lateral-type neurons in segments 5 and 6 that normally form quite robust direct connections to cGI1 and cGI2 (Thompson et al., 1992). These data suggest that En knock-out does not simply transform the identity of $6 \mathrm{~m}$ to that of a lateral segment 6 neuron, such as $6 \mathrm{~d}$, because in this case it would not be expected to lose synapses with cGI1 and cGI2.

Injection of dsRNA shortly after hatching (day 0) removes En protein well after the birth of $6 \mathrm{~m}$ (Fig. 7). However, the effects on synaptic connectivity are very similar to those described above for day -3 injection. As described in our previous study (Fig. 1; Marie et al., 2000a), inappropriate connections to ipsilateral and contralateral GI3 and GI6 are formed, and the connections to GIs 1, 2, and 5 are significantly attenuated (Fig. 9D). Minor differences in the degree of reduction of the GI1 and GI5 EPSPs are evident, but otherwise there is no difference between injection on day -3 and day 0 . Because premitotic and postmitotic knock-out have the same effect, we can conclude that En is required postmitotically to determine the normal pattern of synaptic connections.

Injection of dsRNA at day 3 would not be expected to reduce En levels until after day 4, too late to affect the guidance of the axon and its major branches (see above). However, this treatment does result in significant changes in the pattern of $6 \mathrm{~m}$ synaptic outputs (Fig. 9E). The connections to contralateral GIs 1 and 2 are again significantly reduced in strength, although the synapse with GI5 is not affected. Once again, a de novo connection is formed with contralateral GI3 (Fig. 9E); and weak synaptic connections are made with ipsilateral GI3 in three of seven preparations; and connections with cGI6 are present in five of six preparations (compared with 1 of 10 controls). We conclude that, although day 3 dsRNA injection does not alter the $6 \mathrm{~m}$ axon pathway, its synaptic connections, which form later between days 5 and 6 , are affected.

Injection on day 4 presumably reduces En levels after day 5, approximately the time when synapses are forming (see above). This treatment has no significant effects on the amplitudes of synaptic connections made by $6 \mathrm{~m}$ (Fig. $9 F$ ), suggesting that the reduction in En occurs too late to affect synaptic specificity.

\section{DISCUSSION}

In this study we use the cockroach cercal system to dissect the temporal requirement for the expression of the en gene in a developing identified neuron, $6 \mathrm{~m}$. We describe the development of $6 \mathrm{~m}$ and the rate of disappearance of the En protein after dsRNAi and use these data to knock out En at different times: before the neuron is born and after it sends out an axon, forms an arbor, and makes synapses.

\section{Engrailed knock-out in the precursor does not alter the neuronal fate of $6 \mathrm{~m}$}

The effects of En deletion in other systems give reason to predict that early knock-out of En could perturb the adoption of a 


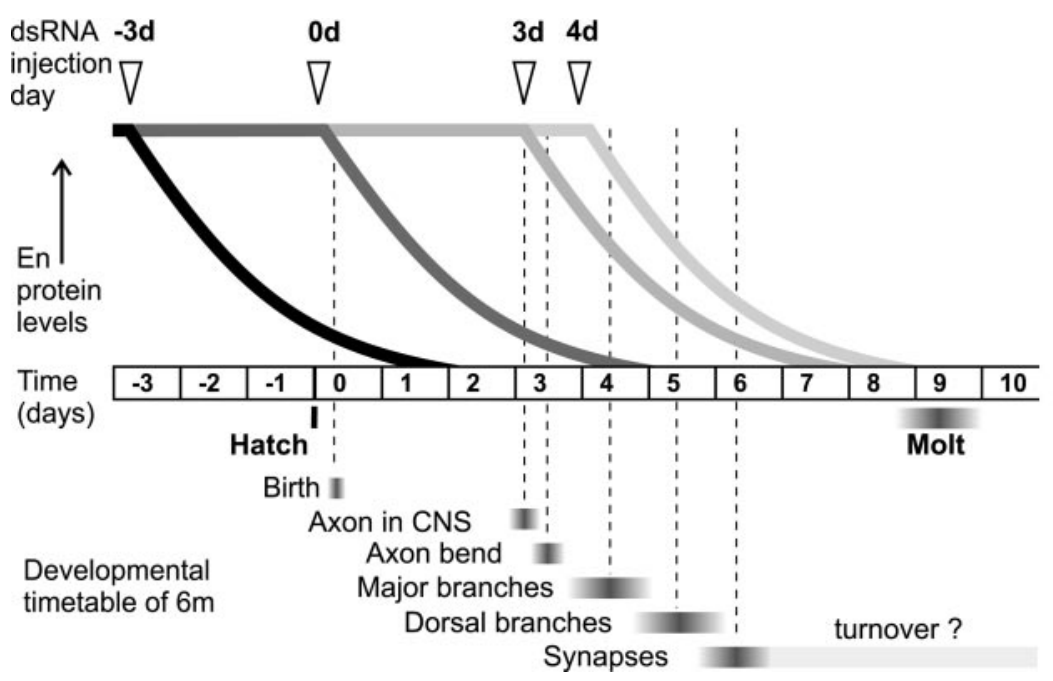

Figure 7. Diagrammatic summary of the developmental timetable of $6 \mathrm{~m}$, showing the experimental times at which dsRNA was injected and the projected time course of En protein removal after each injection.
Developmental timetable of $6 \mathrm{~m}$
1997). In double mutants, dopaminergic midbrain neurons die (Simon et al., 2001).

In the cercus, En is persistently expressed in the medial half of the epidermal field (Blagburn et al., 1995). We have shown that dsRNAi does not change the fate of the neural precursors that arise from this field. There is no change in the numbers or type

Figure 8. Effects on the anatomy of $6 \mathrm{~m}$ of En knock-out at different times. $A-E$, Lucifer yellow filling of $6 \mathrm{~m}$, intensified with antiLucifer yellow antibody and ABCperoxidase. Anterior is at the top, and the ganglionic midline is to the right. Scale bar, $50 \mu \mathrm{m}$. $A$, Wild-type $6 \mathrm{~m}$ arborization. $B$, Transformed $6 \mathrm{~m}$ arbor after dsRNA injection at $3 \mathrm{~d}$ before hatching $(-3 \mathrm{~d})$. $C$, Transformed $6 \mathrm{~m}$ arbor after dsRNA injection immediately after hatching $(0 \mathrm{~d})$. $D$, After injection at $3 \mathrm{~d}$, the $6 \mathrm{~m}$ arbor is not obviously different from the control. E, After injection at $4 \mathrm{~d}$, the $6 \mathrm{~m}$ arbor is identical to the control. $F$, Diagram indicating the angle of the axon bend, measured between defined branch points. Red, Ventral branches; orange, central branches; green, dorsal branches. $G$, We also measured the area of branches ( green) that fell within the anterolateral corner of the cercal glomerulus (dashed box). $H$, The area of branches that enter the dorsal third of the neuropil (green) was measured. I, Quantification of axon angle for $6 \mathrm{~m}$ and $6 \mathrm{~d}$ comparing controls (white bar) with arbors from animals injected at $3 \mathrm{~d}$ before hatching $(-3 \mathrm{~d}$; black bar), at hatching ( $0 \mathrm{~d}$; hatched bar), and at 3 (gray bar) and 4 (light gray bar) d after hatching. Angles from animals injected at -3 and $0 \mathrm{~d}$ are significantly smaller than controls $(* p<0.0005, t$ test). The numbers of preparations were (left to right) four, four, four, three, four, three, and three. Con, Control. J, Quantification of the areas of branches in the anterolateral region of the neuropil. There are significantly more branches in this region in animals injected at $-3,0$, and $3 \mathrm{~d}$ (asterisks: $p<0.0001 ; p=$ $0.002 ; p=0.035$, respectively). $K$, Quantifi-
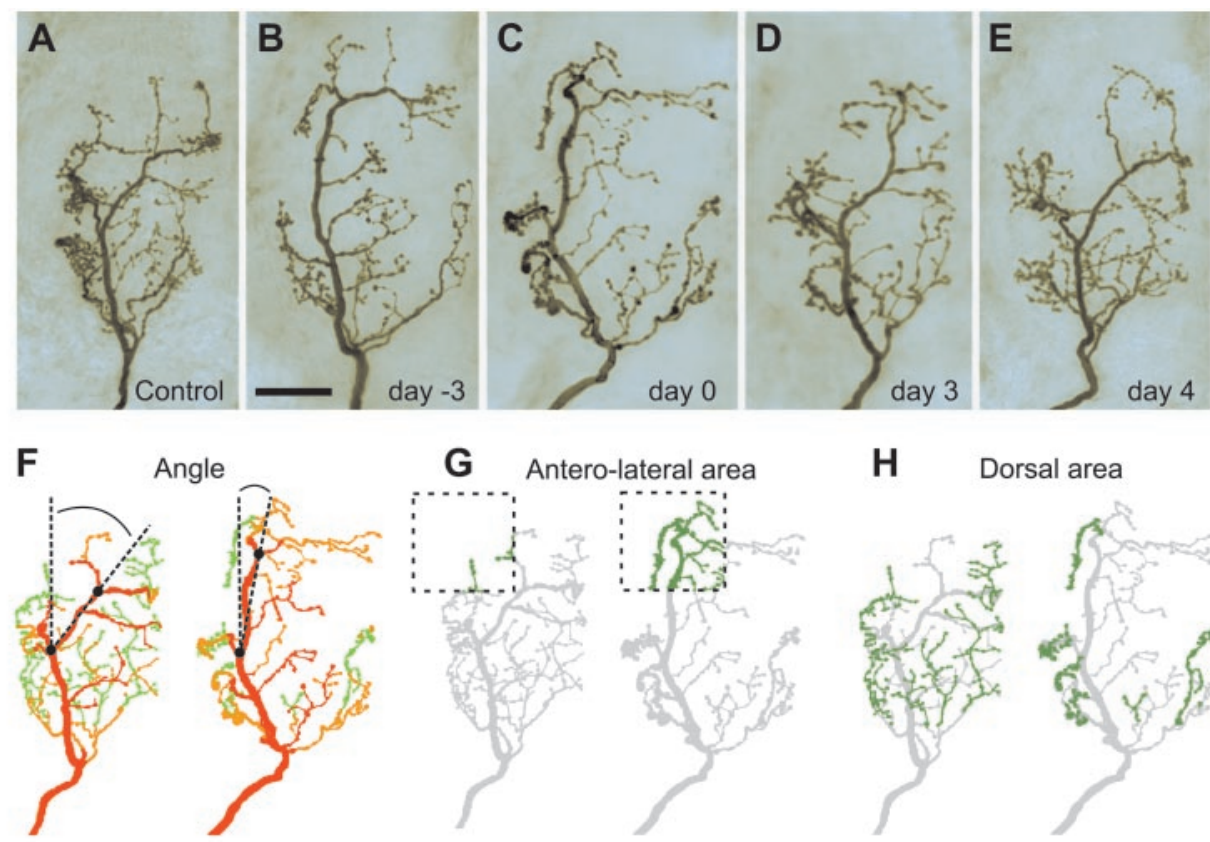

Angle
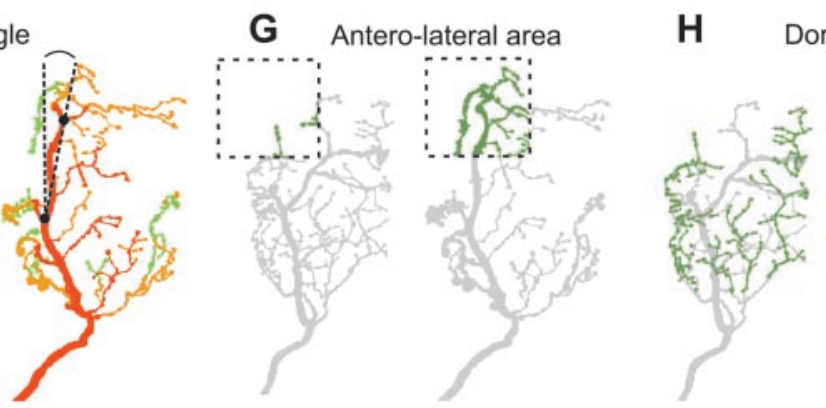

Dorsal area
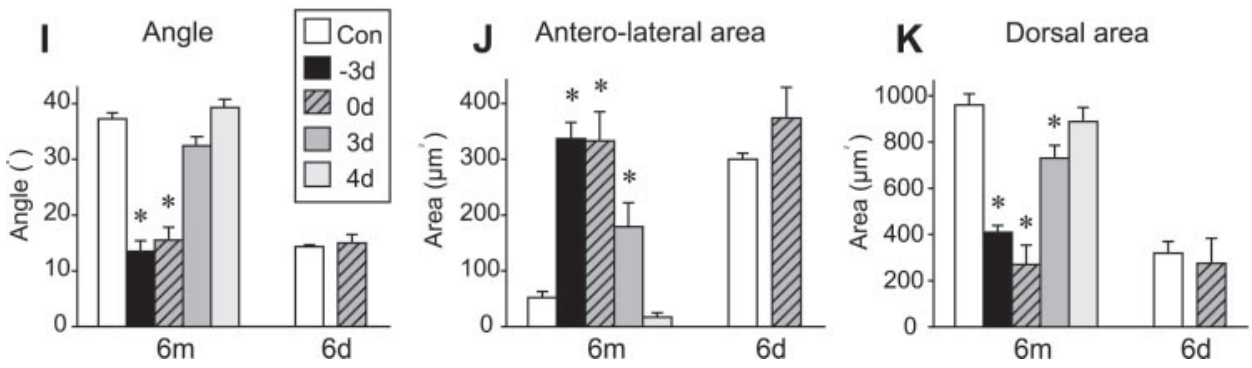

cation of the areas of branches in the dorsal region of the neuropil. There are significantly fewer branches in this region in animals injected at $-3,0$, and $3 \mathrm{~d}$ (asterisks: $p=0.0004 ; p<0.0001 ; p=0.025$, respectively). 

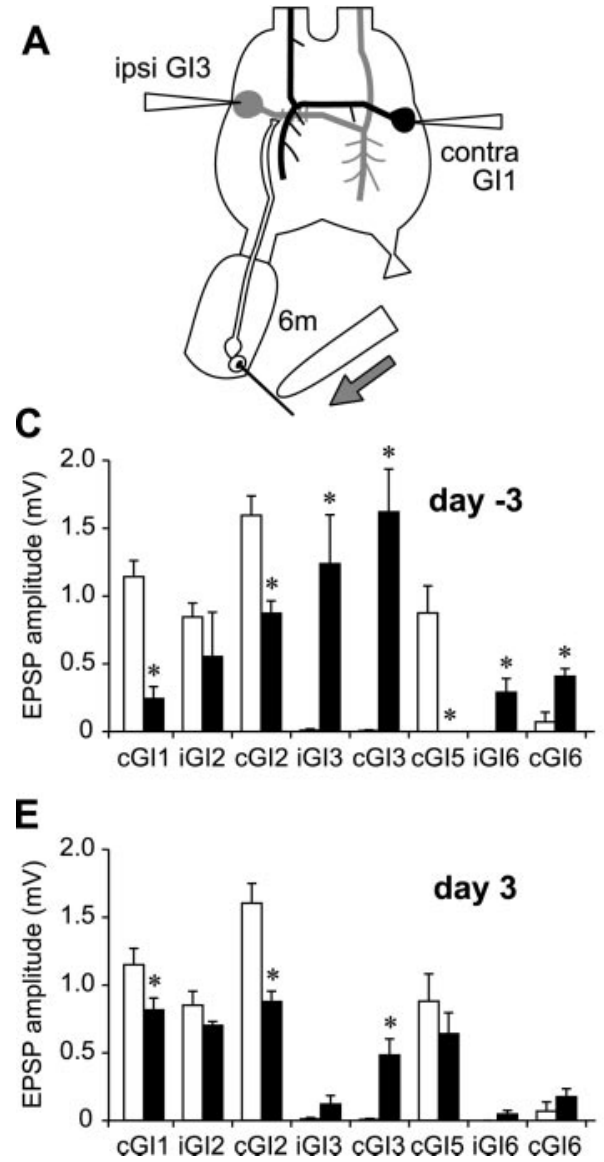
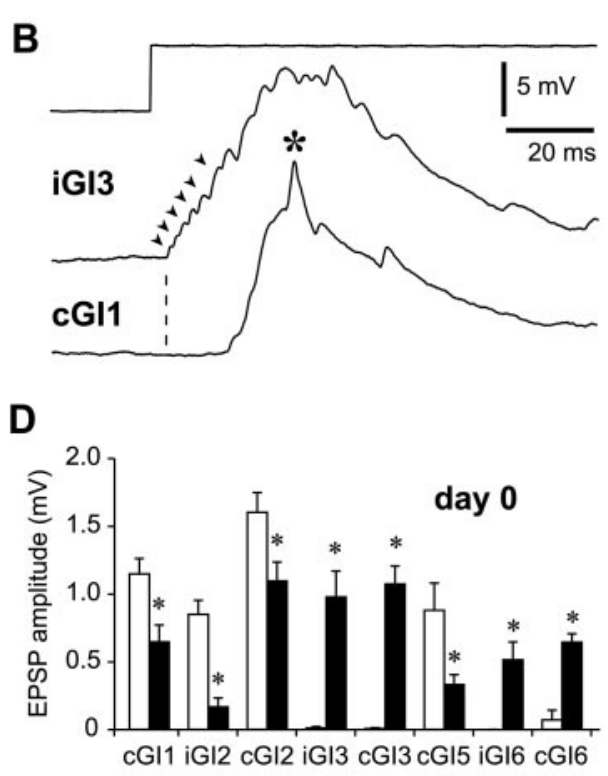

F

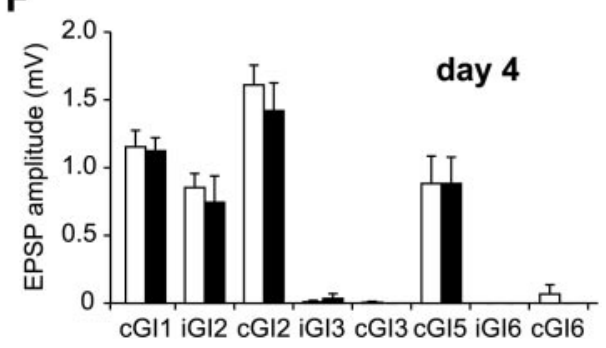

Figure 9. Effects on the synaptic connection of $6 \mathrm{~m}$ of En knock-out at different times. $A$, Diagram of the recording setup. A double intracellular recording was made from different pairs of giant interneurons in the second instar animal [in this case, ipsilateral (ipsi) GI3 and contralateral (contra) GI1] while pushing the hair of $6 \mathrm{~m}$. All other hairs were removed, and the cercus was coated with petroleum jelly. The opposite cercal nerve was crushed. $B$, Typical recording from iGI3 and cGI1 in an animal in which dsRNA was injected $3 \mathrm{~d}$ before hatching. In iGI3 a summating burst of unitary monosynaptic EPSPs (arrowheads) is evident with a short latency after the hair is pushed (upward deflection of the top trace). In cGI1 there are no synchronous monosynaptic inputs, although after a delay a strong polysynaptic excitation is evident, leading to an action potential (asterisk). $C-F$, Bar charts showing the mean amplitudes of $6 \mathrm{~m}$ EPSPs recorded in eight of the GIs, comparing controls (white bars) with treated animals (black bars). Data for ipsilateral GIs 1 and 5 are not shown, because they rarely receive synaptic inputs from $6 \mathrm{~m}$ in control or experimental animals. Error bars indicate SEM. *Significant difference from the control value $(p<0.05)$. In all cases the numbers of control recordings were (left to right) 9, 10, 9, $10,9,8,10$, and 10 . It should be noted that a connection to cGI6 was present in only 1 of 10 preparations. $C$, EPSP amplitudes after dsRNA injection at day -3 . The amplitudes of EPSPs in cGI1, cGI2, and cGI5 are significantly reduced, and de novo connections to iGI3, cGI3, iGI6, and cGI6 are present. The number of experimental recordings was four in all cases. $D$, EPSP amplitudes after dsRNA

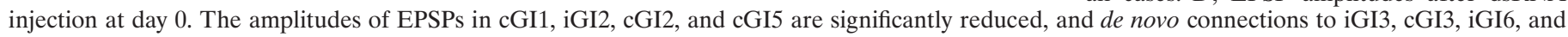

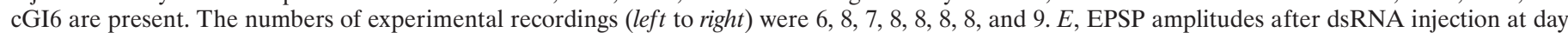

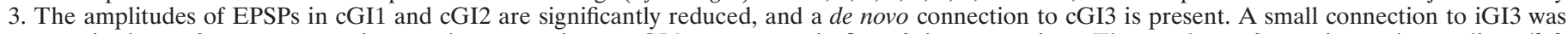

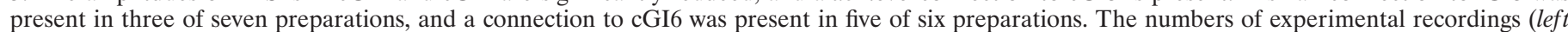

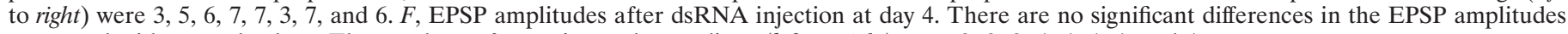
compared with control values. The numbers of experimental recordings (left to right) were 3, 3, 3, 4, 4, 4, 4, and 4.

of neurons, and there is no apparent loss of glial cells; therefore, we conclude that $\mathrm{En}$ is not required for cell survival or to determine the adoption of a neuronal fate. Nevertheless, En knock-out causes the loss of the medial cuticular ridge that divides the dorsal and ventral halves of the cercus, suggesting a conserved role of En in patterning, morphogenesis, or both.

\section{Postmitotic En determines axon pathfinding and synaptic target recognition}

We have shown that the effects of En knock-out are similar whether it is initiated before or after the birth of $6 \mathrm{~m}$, suggesting that En functions postmitotically to control both axonal anatomy and synaptic target choice. The neuron is not committed to the medial subtype by en expression in its embryonic epidermal precursors or its immediate progenitor. In contrast, the axonal projections of sensory neurons in the Drosophila notum are specified by early regional expression of Iroquois complex homeobox genes, before the determination of the sensory mother cells themselves (Gomez-Skarmeta et al., 1996; Grillenzoni et al., 1998).

Although there is evidence that En does not control the axonal projections of Drosophila leg sensory neurons (Murphey et al., 1989), postmitotic neuronal En has been shown to influence axon pathfinding in the Drosophila CNS (Siegler and Jia, 1999) and the vertebrate spinal cord (Saueressig et al., 1999). Wenner et al.
(2000) have raised the possibility that En-1 in postmitotic spinal cord interneurons controls the formation of synaptic connections to motoneurons.

Because our RNAi technique is not cell type-specific, we cannot rule out the possibility that the phenotype of $6 \mathrm{~m}$ may also be determined by noncell-autonomous signals from surrounding epidermal cells that also express en.

\section{En is constantly required to control the axonal branching pattern}

The pathway choice of the $6 \mathrm{~m}$ axon is made on day 3 , when its growth cone reaches the point at which the $\mathrm{L}$ and $\mathrm{M}$ axon tracts diverge. dsRNA injection on day 3 lowers En levels too late to affect bend formation, presumably because the distribution of axon guidance molecules on the growth cone of $6 \mathrm{~m}$ is not affected immediately. The choice of the M pathway appears to be irreversible, because $6 \mathrm{~m}$ is not subsequently able to rejoin the $\mathrm{L}$ tract or to form an ectopic branch along it when it eventually loses En expression, although filopodia actively protrude from the branch point as late as day 5 (Fig. 4).

dsRNA injection on day 3 lowers En levels significantly by day 5 , before the more distal branches of $6 \mathrm{~m}$ are completed. This treatment has an intermediate effect on some of these branches, those in the anterolateral corner of the cercal glomerulus (Fig. 8J) and the dorsal third of the neuropil (Fig. $8 K$ ). Because $6 \mathrm{~m}$ does 
not pioneer any new pathways but instead follows axons that have grown in earlier, the simplest explanation of these results is that En regulates the expression of an adhesion molecule that determines whether the axon of $6 \mathrm{~m}$ fasciculates with L- or M-type afferents. En has been demonstrated to repress the expression of the cell adhesion molecules neuroglian and connectin (Siegler and Jia, 1999); therefore, it is possible that expression of a similar molecule in cockroach sensory axons causes them to follow the branching pattern of preexisting L-type afferents, and that En expression in $6 \mathrm{~m}$ prevents this.

In previous studies, En has been shown to control directly the initial projections of axons (Siegler and Jia, 1999; Saueressig et al., 1999). We show here that En is constantly required for $6 \mathrm{~m}$ not to adopt a default L-type arbor, controlling each successive stage in the formation of its arborization.

\section{Control of synaptic connections by En is independent of axonal anatomy}

Is the influence of En on synaptic connectivity simply a consequence of its effects on axonal anatomy? For $6 \mathrm{~m}$, there is a correlation between its anatomical features and two synaptic outputs: anterolateral branches correlate with the connection to $\mathrm{iGI} 3$, and dorsal branches correlate with the connection to cGI5. However, examination of 25 other second instar neurons showed that there is no general correlation between arbor type and connectivity to the GIs (Thompson et al., 1992).

Our results show that after dsRNA injection on day 3 , the axon of $6 \mathrm{~m}$ follows the normal $\mathrm{M}$ pathway yet makes aberrant synaptic connections, losing synapses with GIs 1 and 2 and gaining a connection to GI3. These interneurons have dendrites primarily in the ventral half of the neuropil (Blagburn, 1989; Blagburn and Thompson, 1990). The branches of $6 \mathrm{~m}$ have penetrated this ventral region before En knock-out on day 5 or 6 . Thus an axon and branches that presumably bear a normal complement of guidance molecules can still form inappropriate synaptic connections, suggesting that the mechanisms for synaptic target recognition are not coupled to those for axon guidance, nor do they use the same cell surface molecules.

Considering our results along with previous anatomical data, we conclude that En controls the expression of synaptic recognition molecules in parallel and independently from those that mediate axon pathfinding.

\section{En knock-out after synapse formation does not change connectivity}

Injection of dsRNA on day 3 had significant effects on the synaptic connections of $6 \mathrm{~m}$; injection on day 4 did not. We know that synapses are formed by day 6, around the time of cuticular apolysis before molting. The most parsimonious explanation for these results is that the levels of En are not reduced enough to allow the formation of inappropriate connections before day 6 , and after that, when En levels have dropped, the period of synapse formation is over. This would agree with the suggestion of Krasne and Lee (1982) that a window of synaptic plasticity occurs only around the time of molting.

Alternatively, it is possible that synaptic connections are continually being remodeled after the initial period of synapse formation. Although individual synaptic contacts in the fly visual system can be lost or gained in a matter of minutes under unusual conditions such as cold shock (Brandstätter and Meinertzhagen, 1995), the normal lifetime of synaptic contacts is unknown. We have assayed for synaptic connections up to $12 \mathrm{~d}$ after day 4
dsRNA injection, and no abnormal synapses were detected. If synapse remodeling occurs during this period, we would have expected to see abnormal synaptic connections, unless there is another mechanism that maintains synaptic specificity, independently of En.

\section{Conclusions}

We have shown that expression of $e n$ by the $6 \mathrm{~m}$ neuron confers a "medial identity" that is defined by a stereotyped axon trajectory and branching and by a specific choice of postsynaptic targets. This is consistent with the chemoaffinity theory of Sperry (1963) that molecular labels direct target recognition and synaptogenesis. A priori, we would have predicted that the positional identity of the sensory neurons would be determined by early exposure to En, before their birth. Instead, the medial neuronal phenotype is determined not in the progenitor but in the postmitotic neuron and in fact can be altered at any stage throughout the course of its development. This constant requirement for En implies that the genes that it regulates are closely downstream and probably code for proteins involved in axon guidance and target recognition. It will be of great interest in the future to try to identify some of these genes in the cercal sensory neurons.

\section{REFERENCES}

Alvarado-Mallart RM (1993) Fate and potentialities of the avian mesencephalic/metencephalic neuroepithelium. J Neurobiol 24:1341-1355.

Arber S, Ladle DR, Lin JH, Frank E, Jessell TM (2000) ETS gene Er81 controls the formation of functional connections between group Ia sensory afferents and motor neurons. Cell 101:485-498.

Blagburn JM (1989) Synaptic specificity in the first instar cockroach: patterns of monosynaptic input from filiform hair afferents to giant interneurons. J Comp Physiol [A] 166:133-142.

Blagburn JM, Thompson KSJ (1990) Specificity of filiform hair afferent synapses onto giant interneurons in Periplaneta americana: anatomy is not a sufficient determinant. J Comp Neurol 302:1-17.

Blagburn JM, Gibbon CR, Bacon JP (1995) Correlation of engrailed expression with sensory neuron identity in the cockroach, Periplaneta americana. J Neurobiol 28:493-505.

Blagburn JM, Sosa MA, Blanco RE (1996) Specificity of identified central synapses in the embryonic cockroach: appropriate connections form before the onset of spontaneous afferent activity. J Comp Neurol 373:511-528.

Brandstätter JH, Meinertzhagen IA (1995) The rapid assembly of synaptic sites in photoreceptor terminals of the fly's optic lobe recovering from cold shock. Proc Natl Acad Sci USA 92:2677-2681.

Condron BG, Patel NH, Zinn K (1994) Engrailed controls glial/neuronal cell fate decisions at the midline of the central nervous system. Neuron 13:541-554.

Fire A, Xu S, Montgomery MK, Kostas SA, Driver SE, Mello CC (1998) Potent and specific genetic interference by double-stranded RNA in Caenorhabditis elegans. Nature 391:806-811.

Friedman GC, O'Leary DDM (1996) Retroviral misexpression of engrailed genes in the optic tectum perturbs the topographic targeting of retinal axons. J Neurosci 16:5498-5509.

Ghysen A, Dambly-Chaudiere C (2000) A genetic programme for neuronal connectivity. Trends Genet 16:221-226.

Gomez-Skarmeta JL, del Corral RD, de la Calle-Mustienes E, FerreMarco D, Modolell J (1996) Araucan and caupolican, two members of the novel iroquois complex, encode homeoproteins that control proneural and vein-forming genes. Cell 85:95-105.

Grillenzoni N, van Helden J, Dambly-Chaudiere C, Ghysen A (1998) The iroquois complex controls the somatotopy of Drosophila notum mechanosensory projections. Development 125:3563-3569.

Hill ES, Blagburn JM (1998) Indirect synaptic inputs from filiform hair sensory neurons contribute to the receptive fields of giant interneurons in the first instar cockroach. J Comp Physiol [A] 183:467-476.

Itasaki N, Nakamura H (1996) A role for gradient en expression in positional specification on the optic tectum. Neuron 16:55-62.

Kania A, Johnson RL, Jessell TM (2000) Coordinate roles for LIM homeobox genes in directing the dorsoventral trajectory of motor axons in the vertebrate limb. Cell 102:161-173.

Kuemerle B, Zanjani H, Joyner A, Herrup K (1997) Pattern deformities and cell loss in Engrailed-2 mutant mice suggest two separate patterning events during cerebellar development. J Neurosci 17:7881-7889.

Krasne FB, Lee SH (1982) Resistance of a crayfish sensory interneurone 
to hyperinnervation by acceptable afferents. J Physiol (Lond) 331:35-49.

Landgraf M, Roy S, Prokop A, VijayRaghavan K, Bate M (1999) Evenskipped determines the dorsal growth of motor axons in Drosophila. Neuron 22:43-52.

Logan C, Wizenmann A, Drescher U, Monschau B, Bonhoeffer F, Lumsden A (1996) Rostral optic tectum acquires caudal characteristics following ectopic engrailed expression. Curr Biol 6:1006-1014.

Marie B, Bacon JP (2000) Two engrailed-related genes in the cockroach: cloning, phylogenetic analysis, expression and isolation of splice variants. Dev Genes Evol 210:436-448.

Marie B, Bacon JP, Blagburn JM (2000a) Double-stranded RNA interference shows that Engrailed controls the synaptic specificity of identified sensory neurons. Curr Biol 10:289-292.

Marie B, Cruz-Orengo L, Blagburn JM (2000b) Analysis of the temporal requirement for Engrailed function in identified sensory neurons: a dsRNA interference study. Soc Neurosci Abstr 26:1598.

Miller DM, Niemeyer C (1995) Expression of the unc-4 homeoprotein in Caenorhabditis elegans motor neurons specifies presynaptic input. Development 121:2877-2886.

Montgomery MK, Xu S, Fire A (1998) RNA as a target of doublestranded RNA-mediated genetic interference in Caenorhabditis elegans. Proc Natl Acad Sci USA 95:15502-15507.

Murphey RK, Possidente DR, Vandervorst P, Ghysen A (1989) Compartments and the topography of leg afferent projections in Drosophila. J Neurosci 9:3209-3217.

Nibbering PH, Marijnen JG, Raap AK, Leijh PC, van Furth R (1986) Quantitative study of enzyme immunocytochemical reactions performed with enzyme conjugates immobilized on nitrocellulose. Histochemistry 84:538-543.

Patel NH, Martin-Blanco E, Coleman KG, Poole SJ, Ellis MC, Kornberg TB, Goodman CS (1989) Expression of engrailed proteins in arthropods, annelids, and chordates. Cell 58:955-968.

Riddiford LM (1993) Hormones and Drosophila development. In: The development of Drosophila melanogaster (Bate M, Martinez Arias A, eds), pp 899-940. Cold Spring Harbor, NY: Cold Spring Harbor Laboratory.

Saueressig H, Burrill J, Goulding M (1999) Engrailed-1 and netrin-1 regulate axon pathfinding by association interneurons that project to motor neurons. Development 126:4201-4212.

Shankland M (1981) Development of a sensory afferent projection in the grasshopper embryo. II. Growth and branching of peripheral sensory axons within the central nervous system. J Embryol Exp Morphol 64:187-209.

Shigetani Y, Funahashi JI, Nakamura H (1997) En-2 regulates the expression of the ligands for Eph type tyrosine kinases in chick embryonic tectum. Neurosci Res 27:211-217.

Siegler MV, Jia XX (1999) Engrailed negatively regulates the expression of cell adhesion molecules Connectin and Neuroglian in embryonic Drosophila nervous system. Neuron 22:265-276.

Simon HH, Saueressig H, Wurst W, Goulding MD, O'Leary DDM (2001) Fate of midbrain dopaminergic neurons controlled by the engrailed genes. J Neurosci 21:3126-3134.

Sperry RW (1963) Chemoaffinity in the orderly growth of nerve fiber patterns and connections. Proc Natl Acad Sci USA 50:703-710.

Thompson KSJ, Blagburn JM, Gibbon CR, Bacon JP (1992) Correlation of filiform hair position with sensory afferent morphology and synaptic connections in the second instar cockroach. J Comp Neurol 320:213-227.

Thor S, Thomas JB (1997) The Drosophila islet gene governs axon pathfinding and neurotransmitter identity. Neuron 18:397-409.

Thor S, Andersson SG, Tomlinson A, Thomas JB (1999) A LIMhomeodomain combinatorial code for motor-neuron pathway selection. Nature 397:76-80.

Wenner P, O’Donovan MJ, Matise MP (2000) Topographical and physiological characterization of interneurons that express Engrailed-1 in the embryonic chick spinal cord. J Neurophysiol 84:2651-2657.

Winnier AR, Meir JYJ, Ross JM, Tavernarakis N, Driscoll M, Ishihara T, Katsura I, Miller DM III (1999) UNC-4/UNC-37-dependent repression of motor neuron-specific genes controls synaptic choice in Caenorhabditis elegans. Genes Dev 13:2774-2786.

Wurst W, Auerbach AB, Joyner AL (1994) Multiple developmental defects in Engrailed-1 mutant mice: an early mid-hindbrain deletion and patterning defects in forelimbs and sternum. Development 120:20652075 . 